\title{
„Comme au cinéma. Le ciel est bleu.“ Zur ästhetischen Tradition der Himmelsschau und ihrer Bedeutung im Frühwerk Jean-Luc Godards
}

\section{Regine Prange}

A tmosphäre lautet einer der Zwischentitel, die in Jean-Luc Godards Une femme mariée (1964) während eines Gesprächs zwischen zwei jungen Mädchen erscheinen, während sie sich über ihre ersten sexuellen Erfahrungen austauschen - belauscht von Charlotte, der weiblichen Hauptfigur des Films. Es handelt sich unverkennbar um eine jener metafilmischen Sequenzen, in denen Godard das Kino selbst kommentiert. Die visuelle und begriffliche Benennung eines stimmungshaften ,Zwischenraums', in dem sich die Suggestion eines geschlossenen Handlungsraums auflöst, gehört zu den wichtigsten künstlerischen Verfahren Godards, die durchweg der Kritik des Erzählkinos gelten. Insbesondere der sich von der Narration distanzierende Blick in den Himmel, Nachbild romantischer Sehnsuchtslandschaften, fungiert als Metapher des kinematografischen Blicks und reklamiert, auf andere Weise als Bazins deep focus-Perspektive, den ,ganzen' Raum als Gegenstand einer alternativen Filmästhetik. Die hier vorgelegte Untersuchung verfolgt die Einführung der Himmelsmetapher in À bout de souffle (1959) und Le Petit Soldat (1960) sowie ihre weitere Entfaltung, vor allem in den Farbfilmen Le Mépris (1962) und Pierrot le fou (1965). Dabei zeigt sich, dass das Motiv des Himmelsblicks seinen utopischen Sinn einerseits durch 
Vergleiche mit älteren Kunstmedien zur Schaffung imaginärer Räume hervorbringt und andererseits mit der Figur des Aussteigers und dem Motiv der heterosexuellen Liebesbeziehung verknüpft ist, die - zum amour fou gesteigert und durchweg scheiternd - zwar die Erfahrung eines euphorisch gestimmten Raums abbildet, diese jedoch durch die gleichzeitig konstatierte Unmöglichkeit auratischer Erfahrung in der späten Moderne bricht.

\section{Der euphorische Raum der Kunst}

Der Himmel, transzendenter Ort der Glückseligkeit, ist auch nach dem Auszug der ,himmlischen Heerscharen“ nicht zum alleinigen Besitz von Naturwissenschaft und moderner Technologie geworden. Während das Zeitalter der Aufklärung, etwa durch die kartografische Erforschung von Wolkenformationen, das mythische Jenseits zu einem faktisch ausmessbaren Raum zu verdiesseitigen begann, hielt die Kunst am emphatischen

$1 \mathrm{Vgl}$. Busch (1995), 463.

2 Bollnow (1963), $230 \mathrm{f}$. und $238 \mathrm{ff}$. Der Begriff des gestimmten Raums geht auf Binswanger (1932) zurück. Zentral für die Diskussion des erlebten Raums in Abgrenzung vom mathematischen ist Heideggers Philosophie, s. dazu Bering/Rooch (2008), Bd. 2, 334-339. Zur „Himmelsheiligkeit" vgl. Eliade (1984), 105 ff.

3 Mit Bezug auf den letzten Band (Die wiedergefundene Zeit) zit. n. Bollnow (1945), 202.

4 Bollnow (1963), 220, mit Bezug auf Nietzsches Zaratbustra.
Bild des Numinosen fest. ${ }^{1}$ Als Hauptgegenstand romantischer Landschaftskunst, exemplarisch bei Caspar David Friedrich, repräsentiert die Himmelssphäre den imaginären Raum bürgerlicher Sehnsucht, welche einer ästhetischen Rückgewinnung der verlorenen Einheit von Mensch und Kosmos gilt. Diese Utopie, die auch Basis politischer Visionen einer versöhnten Gesellschaft ist, lässt sich mit Orientierung an Otto Friedrich Bollnows Begrifflichkeit als Reformulierung der religiösen Himmelsschau im Modus des "gestimmten Raums“ und speziell des „euphorischen Raums" begreifen. ${ }^{2}$ Ferne, Höhe und Bläue des Himmels werden von Autoren der Moderne nicht selten jener außerordentlichen Stimmungslage zugeordnet, die - paradox - als flüchtiges Erlebnis der Ewigkeit in der Zeitlichkeit das Erbe der religiösen Heilserfahrung antritt.

Eine tiefe Glückserfahrung nennt das Erzähler-Ich in Marcel Prousts Roman Auf der Suche nach der verlorenen Zeit (1913-1927) „eine Vision von Azur". ${ }^{3}$ Sie meint die "wiedergewonnene" Zeit der inneren Einheit des Selbst, das sich in zufälligen, unkontrollierbaren Momenten der Erinnerung als mit seinem früheren Leben identisch erfährt. Gegenwart und Vergangenheit verschmelzen. Als Beleg für die Psychisierung der Seligkeit führt Bollnow auch Nietzsches Lehre vom „Großen Mittag“ an, die mit dem Erlebnis jener Tageszeit ebenfalls das Glück der Entrückung aus dem alltäglichen Lauf der Zeit verbindet. Eine tiefe Ambiguität ist dieser Anschauung der Ewigkeit jedoch eigen, die als „heiter und schauerlich“ oder auch als „heiter-tiefer Himmel“ beschrieben wird. ${ }^{4}$ Besonders im 
Blick auf Nietzsches Forderung, „einen hellen glänzenden geheimnisvollen Himmel des Südens über sich aus[zu]spannen "5, wird zudem die Analogie zur Malerei seit Delacroix deutlich, die in den Ländern des Südens, vornehmlich in Italien, das Erlebnis von Licht und Farbe suchte nichts anderes als die lebensweltliche Realität der ästhetischen Erfahrung. Nur sie kann noch, nach dem Verlust einer bindenden Religiosität, Generator euphorischer Gestimmtheit sein, dem Erleben zeitlicher wie räumlicher Ferne.

Der Himmelsfarbe Blau kommt nicht von ungefähr im Werk des Protagonisten der klassischen Moderne - Paul Cézanne - eine besondere Bedeutung zu. Sich dem perspektivischen Versprechen der Nähe entgegenstellend, distanzierte er den Bildraum vom Betrachter, indem er das Blau als Fundament der gesamten Farbigkeit einsetzte und es dadurch von seinem luftperspektivischen Darstellungswert löste. So Kurt Badt:

[D]ie Dinge, selbst jene, die die Bestrablung einer vollen südlichen Sonne empfangen, [...] existieren doch in einem verschatteten Dasein, darin aber mit besonderer Kraft. [...] In einer Weltdarstellung, in welcher der Zusammenhang der Dinge durch blaue Schattenbahnen aufgezeigt und alle Farbigkeit vom blauen Schatten ber bestimmt ist, entbüllt sich die Erde und die Kreatur als ungreifbar, unerreichbar, weil sie wesensmäßig der Ferne verhaftet ist. ${ }^{6}$

Auch wenn Badt dessen Terminologie nicht verwendet, liegt der Verweis auf Alois Riegl nahe, der die impressionistische und postimpressionistische Malerei als Kulmination des optischen Kunstwollens in einer Kunst der Stimmung bewertet hat. Dass in diesem Sinne räumliche Relationen das haptisch-sinnliche Körpererleben ersetzen, begründete Riegl durch die Schilderung seiner eigenen Blickerfahrung in die Ferne einer Alpenlandschaft. An die Stelle der fabula, die das Augenmerk auf einzelne Handlungsmomente richtet, tritt die jede Vereinzelung aufhebende „beruhigende Überzeugung vom unverrückbaren Walten des Naturgesetzes. " 7

Die Metapher der Ferne findet sich auch in Walter Benjamins Begriff der Aura wieder, der das Kunstwerk als „einmalige Erscheinung einer Ferne, so nah sie sein mag“, bestimmt. ${ }^{8}$ Diese Definition eines atmosphärischen Wahrnehmungserlebens, das in die Ferne von Raum und Zeit hineinreicht, wird zwar zunächst landschaftsästhetisch begründet, hat aber ihren Ursprung, wie Benjamin weiter ausführt, in der Qualität des Heiligen. „Nicht Sichtbarkeit, sondern ,Unnahbarkeit‘ ist die Hauptqualität des archaischen Kultbilds, das als paradoxe Einheit von Entzug und

5 Zit. n. Bollnow (1963), 230, mit Bezug auf Nietzsches Willen zur Macht.

6 Badt (1956), 62.

7 Riegl (1899), 35. Zur Korrelation der Fernsicht mit der Stilkategorie des Optischen vgl. Prange (2010b), bes. $110 \mathrm{ff}$.

8 Benjamin (1936), 440. Zum Begriff der Aura unter dem Aspekt einer Ästhetik der Atmosphäre vgl. Böhme (1993), 116 ff. Zum Verhältnis von Benjamins AuraKonzept zu Riegls Stimmungs-Aufsatz vgl. von Arburg (2010), 13 ff. 
9 Lindner (2006), 237. Zur Begründung der Aura im Kult vgl. Benjamin (1939), 480.

10 Hierzu ausführlich Prange (2006), 233-267

11 Vgl. Sylvester (1992), Nr. 166.
Präsenz, Unantastbarkeit und Berührung wirksam ist. ${ }^{\text {"9 }}$ Der auratischen Wahrnehmung wird allerdings von Benjamin - und darin unterscheidet sich seine Konzeption nicht nur von Riegls Stimmungsbegriff, sondern auch von Heideggers, Bollnows und Böhmes Ästhetiken der Atmosphäre die Diagnose einer dem Industriezeitalter geschuldeten Aura-Krise an die Seite gestellt, welche maßgeblich durch die moderne Technik, insbesondere die Reproduktionstechnologien Fotografie und Film, hervorgebracht werde. Die Katastrophe des Ersten Weltkriegs hat, so Benjamin, eine radikale Verkümmerung von Erfahrung hinterlassen. An ihre Stelle sei eine Überfülle der Reize und eine diese abwehrende permanente Schockbewältigung getreten, die eine Verbindung zu den unbewussten Erinnerungen nicht mehr zulasse. Dem Künstler als ,neuem Barbaren wird auf der Grundlage des solcherart extrem geschärften Bewusstseins jedoch die Kompetenz zugetraut, nach dem Modell Prousts jene mémoires involontaires zu aktivieren, eine archaische Erfahrungsschicht zu mobilisieren, in der das Gegenwärtige mit dem Vergangenen zusammenfließt. Theodor W. Adorno hat Benjamins These des Aurazerfalls seinerseits für eine Theorie der Kunst adaptiert, die ihrem eigenen Begriff und insbesondere ihrem Totalitätsanspruch kritisch gegenübertritt und so in der Negation die auratische Erfahrung bewahrt. ${ }^{10}$

Von den avancierten Kunstbewegungen des 20. Jahrhunderts ist die ästhetische Aneignung des Himmels und seines Glücksversprechens entsprechend unter den Vorbehalt gestellt worden, dass diese Aneignung selbst zum Gegenstand der Kunst wird, so dass letztere ihre Berechtigung nur durch die kritische Reflexion ihrer Option auf das Absolute gewinnen kann. René Magrittes gemalte Collagen etwa behandeln den Himmel wie ein Versatzstück, das zwar die romantische Tradition der Himmelsschau zitiert, sie jedoch in der pointierten Buchstäblichkeit der Montage negiert. Als ein frühes Beispiel wäre das Ölgemälde Les muscles célestes (1927) zu nennen, das aus der Sphäre des wolkigen Himmels figural-ornamentale Gebilde ,ausfließen' lässt, die sich auf einer perspektivischen Bühne wie Körper bewegen und Schatten werfen. ${ }^{11}$

Spätestens durch die explosionsartige Entwicklung der Kulturindustrie nach dem Zweiten Weltkrieg ist der romantisch fotografierte Himmel zum Massenartikel verkommen. Die Kunst muss gegen eine scheinheilige Stimmungsproduktion anarbeiten, die das technologisch fabrizierte Bild des Glücks den Marktinteressen der Tourismus-Industrie dienstbar macht. Künstlerischer Avantgardismus lässt sich an diesem historischen Punkt nicht zuletzt definieren durch die Auseinandersetzung mit einer 
universal gewordenen Ästhetik der Stimmung; sie ist nicht ein bloßer Teil von ihr. So hat sich exemplarisch Gerhard Richter in seiner Fotomalerei jenem in die Trivialität abgesunkenen Himmelsblick zugewandt. Fotografien des Himmels werden von ihm ebenso als Ready Made wahrgenommen und verarbeitet wie Fotografien aus Familienalben oder aus Illustrierten, die das sentimentale Gefühl gleichfalls im Abbild festhalten wollen und dabei auf konventionalisierte Traditionen der Malerei zurückgreifen. Das monumentale Gemälde Wolken (Stimmung) $(1970)^{12}$ zum Beispiel verbirgt keineswegs seine Vorlage, das fotografische Abbild eines Wolkenhimmels im Gegenlicht. Doch indem Richter die malerische Textur ebenso sichtbar jene Vorlage reproduzieren und transformieren lässt, kreuzt er die dokumentarisch-fotografische mit der malerischen Reproduktion, wobei letztere keine Übermacht gegenüber der ersteren gewinnt. Der Wahrheitsanspruch des mechanisch, auf technologischer Basis erzeugten Abbilds bricht sich an der authentischen Stofflichkeit des malerischen Helldunkels. Die Gegenwart des beliebig verfügbaren Fotos kollidiert mit der anachronistischen Vergegenwärtigung des historischen Mediums der Ölmalerei und seinem monumentalen Anspruch, so dass in dieser irritierenden Begegnung die Kontinuität der Sehnsucht nach dem euphorischen Augenblick bewusst und nicht lediglich konsumiert werden kann. Die Verschränkung der fotografischen mit der malerischen Oberfläche dementiert die Transparenz des Bildes.

Der Himmel ist in den Landschaften Richters, zu denen auch zahlreiche See-Stücke zählen, mithin ein sinnfälliges Modell des abstrakten ästhetischen Raums, dessen emotionaler Appell an die Betrachter im Modus der romantischen Fernsicht, in dem angeführten Werk nachdrücklich auch durch das Stichwort „Stimmung“ im Untertitel, explizit als Konvention vorgetragen wird. ${ }^{13}$ Eindrücklich ist damit der Abstand zu jener Erfahrung eines ,untiefen' Raums bezeichnet, wie sie Magritte im Sinne des romantischen Mythos eines unschuldigen Sehens vorgetragen hat. Er glaubte, „den am Himmel fliegenden Vogel greifen zu können" und verwies auf Paul Valéry, der erfahren habe, wie sich das Meer „vor den Augen des Betrachters erhebt. "14 Richter reinszeniert hingegen die Entrücktheit des einst von Cézanne kreierten und als Ausdruck unmittelbarer Wirklichkeitserfahrung verklärten modernistischen Flächenraums auf postmoderner Grundlage, d. h. unter radikalem Verzicht auf eine originäre, im direkten Kontakt mit ,Natur ${ }^{\varsigma}$ erarbeitete Gestaltung.
12 Vgl. Richter (1993), Bd. 3, Nr. 264.

13 Zu den Landschaften Richters vgl. u. a. Elger (1999). Vgl. das Ölgemälde Abendstimmung (1969), abgebildet in Elger (1999), 54.

14 Magritte (1985), 82. 


\section{Godards Himmel: À bout de souffle}

Jean-Luc Godard verlieh dem romantisch grundierten Bild des Himmels eine radikal ikonoklastische Schlagkraft, indem er dessen transindividuellen Stimmungscharakter gegen die psychologische Rhetorik des Erzählkinos wendete. Der nächtliche wie der mittäglich durchsonnte Himmel sind nicht lediglich Teil des diegetischen Raums bzw. Dokument der Natur, sondern Bild der Filmkunst, die in den Vergleich mit älteren Künsten wie der Malerei eintritt, um sich mit ihren Methoden zur Schaffung eines räumlichen Totalitätserlebens zu messen. Godard erschließt diese wie andere metafilmische Bedeutungsebenen stets in der Form des Zitats; der Himmel als Utopie eines, anderen' Lebens ist nicht direkter Anschauung zugänglich, sondern nur vermittelt durch den Rekurs auf bereits sedimentierte ästhetische Erfahrung.

Hier soll zunächst deutlich gemacht werden, auf welche Weise Godard die Himmelsmetaphorik in seinen frühen Filmen einführt. Dabei wird sich, analog zu Richters metapicturaler Himmelsmalerei, nicht nur die eindrucksvolle Konsistenz jener Repräsentation des filmischen Raums durch den auratischen Himmelsraum erweisen. Auch die damit verbundene, in Lefebvres Theorie formulierte kongeniale Einsicht in die gesellschaftliche Produziertheit des Raums wird in der Verschränkung des Fiktionalen mit

15 Henri Lefebvre konzipierte auf der Grundlage eines marxistischen Geschichtsmodells eine Entwicklung vom ,absoluten Raum' religiös gebundener Gesellschaften zum ,abstrakten Raum'der (kapitalistischen) Neuzeit, der durch den Widerspruch zwischen Homogenisierung und Fragmentierung geprägt sei; vgl. Lefebvre (1991).

16 Das Argument wird ausgeführt in Prange (2010d). dem Dokumentarischen permanent zum Thema gemacht. ${ }^{15}$

Der ästhetische Raum ist von Anfang an auf die Figur des Aussteigers bezogen, der nicht lediglich als Rollenfigur gemeint ist, sondern dessen Aussteigertum zugleich immer auch den Bruch mit den Normen des Erzählkinos spiegelt. Das erste Himmelsbild ist in diesem Sinne bereits ein ikonoklastisches. In $A$ bout de souffle macht sich Michel Poiccard (Jean-Paul Belmondo) mit einem gestohlenen Auto auf den Weg nach Paris, wo er die amerikanische Studentin Patricia Franchini (Jean Seberg) treffen will, um sie zu überreden, mit ihm in den Süden zu fahren. Im Handschuhfach entdeckt er einen Revolver, mit dem er wenig später einen Polizisten töten wird, was den Gang der Handlung und den Tod des Protagonisten geradezu zwangsläufig vorbestimmt. Der Revolver ist nicht nur Instrument und Ausweis der Genre-Logik, sondern auch symbolischer Stellvertreter der Kamera, so wie die Autofahrt die Kamerabewegung bzw. das Kinoerlebnis als Erlebnis eines dynamisierten Raums zitiert. ${ }^{16}$ Mit den Worten „C'est beau le soleil“ schießt Michel im Übermut auf die Sonne, die sich im Laub der Bäume bricht. Während mehrere Schüsse aus dem Off ertönen, versucht die Kamera vergeblich, 
das Zielobjekt zu fokussieren. Die Einstellung beginnt mit einem noch durch das Autofenster gerahmten Ausblick auf die vorbeirasenden Bäume im Gegenlicht. Nach einem kurzen Schwenk ist leinwandfüllend nur noch das in verschwommene Schattenwerte aufgelöste Laub zu sehen, das schließlich am Ende der Einstellung vom Sonnenlicht überstrahlt wird. Der euphorische Raum entzieht sich der Sichtbarkeit. Der Effekt des sich in der Kameralinse reflektierenden Sonnenlichts zeigt demonstrativ die technischen Grenzen der filmischen Aufnahmetechnik. Später hat Godard diesen Effekt noch gezielter als Hinweis auf die apparative Verfasstheit des filmischen Bildes im Vergleich zum (filmisch nachgestellten) malerischen Bild eingesetzt. In Passion (1982) folgt eine vergleichbare Passierfahrt auf die (fehlschlagende) Inszenierung von Rembrandts Nachtwache. Der Blick (der Kamera) in die Sonne, also gleichsam auf die Quelle des fotografischen und damit auch des filmischen Bildes, erzeugt eine abstrakt-kristalline Reflexform, lässt Transparenz in Opazität umschlagen.

In $\grave{A}$ bout de souffle antizipieren die beschriebenen Schüsse aus dem Off jene Szenen, in denen das Kino auch im diegetischen Raum platziert wird. Zum Beispiel sind, während Patricia und Michel sich in einer Westernvorführung küssen, ebenfalls Schüsse zu hören - Signal dafür, dass auch dieser Kuss den Gesetzen des Genrekinos folgt. ${ }^{17}$ Die Aufdeckung seiner Regelhaftigkeit kommt dem Eingeständnis gleich, dass ,nichts' zu sehen ist, was im geblendeten Blick in die Sonne, aber auch im Bild des Nachthimmels seit Godards erstem Spielfilm immer wieder Thema ist. Nach ihrem Kinobesuch, und freilich als dessen metafilmischer Kommentar gemeint, betrachten Michel und Patricia die nächtliche Place de la Concorde: „Oui, c'est mystérieux toutes les lumières“, bejaht Patricia Michels Äußerung über die Schönheit des Platzes, die seiner früheren Bemerkung über die Schönheit der Sonne gleicht. Das Geheimnis des Nachthimmels ist also Bestandteil eines Dialogs und damit dem narrativen Raum inhärent. Zugleich wird es aber auch, mithilfe der kamerasymbolischen Autofahrt, auf den ästhetischen Raum schlechthin, das ,Wunder der Kunst beziehbar, dessen Realität hier gleichsam parallel zur Diegese in einem quasi-dokumentarischen Report über die erlebte Attraktion der Pariser Platzanlage aufgerufen wird.

Die einst vom Kunstwerk ausgehende "Macht eines Wunders“ besteht gemäß Schellings romantischer Kunstphilosophie darin, dass sie im Betrachter „mit plötzlicher Klarheit die Erinnerung von der ursprünglichen Einheit des Wesens der Natur mit dem Wesen der Seele“

17 Für weitere Ausführungen vgl. Prange (2010d). 
18 Schelling (1807), 605, mit Bezug auf die antike Skulptur der Niobe.

19 Vgl. Benjamin (1936), 440 .

$20 \mathrm{Vgl}$. Lindner (2006), 236.

21 Zum „Nachtraum“ als ausdehnungslosem Raum im Gegensatz zum „Tagraum“ vgl. Bollnow (1963), 224228. Zum „Raum des liebenden Zusammenlebens" nach Binswanger vgl. Bollnow (1963), 257-264. Zur Konzeption der leidenschaftlichen Liebe als Spur des Heiligen vgl. Wulf (1987).

$22 \mathrm{Zu}$ diesem Vorwurf grundsätzlich Brown (1972).

23 Vgl. Benjamin (1939), $495 \mathrm{f}$. weckt. ${ }^{18}$ Eine solche machtvolle Gegenwart prägt auch noch die Wahrnehmung jenes „Gebirgszug[s] am Horizont", die Benjamin als Exempel der Aura anführt. ${ }^{19}$ Sie ist schließlich, wenngleich der Ursprungsgedanke strittig ist, dem Hier und Jetzt des Kunstwerks eingeschrieben, das Benjamin, Heidegger und Adorno übereinstimmend als sein „Erscheinen“ definierten. ${ }^{20}$ Godard belegt gewissermaßen die aktuelle Brisanz dieses Topos der philosophischen Ästhetik, indem er sein (allerdings bruchstückhaftes) Nachleben in Gestalt einer scheinbar beiläufig aufgezeichneten lebensweltlichen Erfahrung des Wunderbaren beschreibt, die doch nicht weniger impliziert als eine radikale Erweiterung des auf narrative Bezüge begrenzten filmischen Raums. Der Nachthimmel ist, durchaus im Rahmen der Diegese, negativer Vorschein jener Freiheit des Südens, zu der sich das Paar nun aufmachen will. Seine ästhetische Wahrnehmung repräsentiert durch ihren metaphysischen Akzent darüber hinaus den utopischen Raum der Liebe und den eines ,anderen ' Lebens. ${ }^{21}$

Unabweisbar ist schon hier, dass die metafilmische Argumentation Godards in sich höchst komplex ist und keineswegs als pauschale entleerte Form der Selbstbezüglichkeit betrachtet werden darf. ${ }^{22}$ Es geht darum, den Film in die romantisch-moderne Tradition der Kunst und ihrer ästhetischen Utopie eines euphorischen Raums zu stellen, dessen Darstellbarkeit an die Unmöglichkeit seiner Visualisierung, das Verschwinden der Objektgrenzen geknüpft wird. Der Blick in die Sonne und das Geheimnis des Nachthimmels konterkarieren die aristotelische Logik des Genrekinos. Zugleich bilden sie ,magische` Kontrapunkte zu einer dokumentarischen Ästhetik, die ihrerseits, im Sinne von Benjamins Notiz über den Chirurgenblick der Kamera ${ }^{23}$, in das Gewebe der Wirklichkeit eindringend die Genreformel aushöhlt, vor allem aber als Gegenpol zur Malerei postuliert worden ist, die anders als der Film ein unversehrtes Raumganzes präsentiert. Im Rahmen dieser Logik bemüht Godard neben seinen viel besprochenen explizit dokumentarischen Stilmitteln den Rekurs auf die ,fernsichtige 'Malerei und ihren Totalitätsanspruch.

\section{Malerei und Film: Le Petit Soldat}

Nachfolger Michel Poiccards, der seiner Ganovenrolle nicht gerecht wurde, weil er Patricia Franchini liebte, ist der ,kleine Soldat' Bruno Forestier (Michel Subor), Fotojournalist und Agent der rechtsextremen OAS, der seinen Mordauftrag nicht ausführen und stattdessen mit Veronica Dreyer (Anna Karina) nach Brasilien fliegen und dort leben will. Schon hier 
erscheint im Übrigen das Motiv des Flugzeugs, dem in Une femme mariée, Passion und Je vous salue, Marie (1985) weitere Bedeutsamkeit verliehen wird, als Vehikel der Flucht in einen imaginären Raum, der gleichermaBen durch die Liebe wie durch die Kunst konstituiert wird. Kurz nach seiner Ankunft in Genf, nachdem der Off-Kommentar des Ich-Erzählers bereits die Zweifel des Protagonisten an seiner Rolle und seine Suche nach dem ,Wesentlichen' angedeutet hat, gibt dieser sich als Kunstliebhaber zu erkennen: „Das Dunkelblau des Himmels hat mich an das Bild von Paul Klee erinnert Woher kommst Du? Wo bist Du? Wobin gebst Du?

$\mathrm{Zu}$ sehen gibt es eine von Straßenlaternen, Lichtreklamen, Ampeln und Autoscheinwerfern erhellte abendliche Straßenkreuzung. Die in Aufsicht gedrehte Totale zeigt, wie Bruno in seinem Cabriolet nach links auf die Brücke abbiegt und verschwindet. Statt ihm zu folgen und ihn gemäß der Kontinuitätsregel des Erzählkinos als handlungsmächtiges Subjekt zu fokussieren, verharrt die Kamera und schwenkt nur ein wenig aufwärts gen Himmel (Abb.1), während das tiefe Blau in Klees Bild durch den voice over-Kommentar Erwähnung findet. Passanten überqueren die Straße. Stromleitungen durchkreuzen den Himmel. Lichter spiegeln sich auf einer Wasseroberfläche. Das dokumentarische Bild der Verkehrsströme verselbständigt sich gegenüber der Spielhandlung, als ein dem Blau der Ferne subsumiertes inneres Stimmungsbild, dem die Melancholie des Sprechers korrespondiert und das so in eine irritierende Deckung gebracht wird mit dem Bild Klees (Abb.2), von dem wir zunächst nur den Titel erfahren. Die mit ihm gestellten Fragen „Woher? Wo? Wohin?" sind die Fragen nach dem Ursprung und Sinn des Lebens, Fragen, die traditionell Philosophie und Religion zu beantworten versucht haben. Ihre Übernahme in die bildkünstlerische Artikulation jenseits konfessioneller Mythologeme leistete exemplarisch Paul Gauguins symbolistisches Monumentalwerk Woher kommen wir? Wer sind wir? Wohin gehen wir? (1897). Auf jenes Werk, das auch Godard sicherlich bekannt war, dürften Klees lakonisch verkürzte Titelfragen Bezug nehmen. In Le Petit Soldat zitiert der Protagonist Klees Titel aber falsch und scheint ihn mit Gauguins Titelwahl zu vermischen. Durch dieses Zitatverhältnis wird schon klar, dass sich beide, Klee wie Godard, nicht bruchlos in die Tradition der historischen Avantgarden und deren ästhetische Aneignung des sakralen Raums stellen, sondern den metaphysischen Gestus dieser Aneignung zurückweisen. Godard referiert deshalb auf Klees Transformation des Gauguinschen Gemäldes, weil sie für seine eigene Kritik der aristotelischen Ästhetik ein Modell bietet. 
Wo Gauguin die Aspekte des Titels in statuarischen Figuren und Figurengruppen erzählend andeutet und etwa den Blick aus dem Bild als Visualisierung der Frage in verschiedenen Lebensaltern in Szene setzt, überdies die ,Himmelsfarbe‘ Blau der steinernen Göttin und das irdische Ocker den jungen Menschen zuordnet, verdichtet Klee die zeitlich-räumlichen Momente jener existentiellen Fragen in einer einzigen Figur, die somit als Figur im tradierten Sinne nicht mehr gelten kann. Die Mitte der Gestalt ist in flächige, geradezu labyrinthisch anmutende Facetten zersetzt, die einen wuchtigen frontal gesehenen Oberkörper von einem kindlich proportionierten Beinpaar trennt, das eine klare Schreitbewegung nach rechts ausführt, also die Frage nach dem „Wohin?“ einzulösen scheint. Das Missverhältnis zwischen dieser klaren Richtungsangabe, dem wuchernden Labyrinth des Leibes und dem wie in melancholischer Versunkenheit in die andere Richtung nach unten gewandten Kopf stiftet jene ironische Pointe, die Klees Werken oftmals eigen ist. Entscheidend gerade im Spätwerk ist dabei die demonstrative Ausstellung der Materialität von Zeichnung (Kreide), Farbe (Aquarellfarbe und Rötel) und Bildträger (Papier und Karton). Nirgendwo bleibt die Montage der verschiedenen Materialien verborgen. Die Farbe, welche traditionell, auch noch in Gauguins Figurenbild, der Zeichnung sinnliche Präsenz verleiht, also für die suggestive Autonomie der Darstellung sorgen soll, ist von dieser Aufgabe entbunden und wird selbst machtvolle Präsenz. In diesem Sinne zitiert Bruno in Le Petit Soldat „das tiefe Blau“ Klees. Die exklusive Nennung der Farbe bezeichnet die auch Godard eigene semi-abstrakte künstlerische Methode Klees. Das Blau durchdringt partiell die Figur, es intensiviert ihre Dissoziation, verhindert die gestalthafte Ablösung vom Hintergrund. Über das gesamte Blatt verteilt finden sich überdies bräunliche Flecken, die durch die Technik des Abpausens entstanden, also in einem gewissen Ausmaß Dokument des Zufalls sind und zugleich auch als Zeichen für Alterung und Verwitterung gelesen werden können.

Ich resümiere: Nicht die Bildfigur bzw. in Analogie hierzu der Filmcharakter entlässt aus einem psychischen Inneren Ausdruck und Bewegung. Die psychologische Affekterzählung des Historienbildes wie des Spielfilms wird vielmehr als Mythos selbst Gegenstand der Darstellung. Weder bei Klee noch bei Godard gibt es selbständig agierende, vom Grund, also von ihrer Konstruiertheit fiktiv entbundene Figuren. Das Goldene Zeitalter, das Gauguin in dem monumentalen Orangenpflücker und dem auf der Erde sitzenden Kind, das einen Apfel isst, szenisch verdichtet, gibt es in Klees und Godards Bildern nur als Fragment, als Zitat 
in einem Konglomerat aus Zitaten. Mit der Ausschließlichkeit und Deutlichkeit der Zitatform tritt aber konsequenterweise zugleich der Realraum an die Stelle des fiktionalen: das filmische Dokument alltäglicher Realität bei Godard, die Materialität und künstlerische Technik bei Klee. Die Farbe Blau ist in seinem Aquarell so aufgetragen, dass sie sich nicht zum Raum entleert, also als Substanz wirkt; gleichwohl evoziert sie, als versehrte, körperlich gewordene Farbe, die erhabene Gestimmtheit des Himmels. Ähnlich bindet Godard die ,Wirklichkeit' einer städtischen Verkehrssituation an die ikonische Referenz der Himmelsbläue. Dem Schwarz-Weiß-Film mit seiner Konnotation der authentisch historischen Aufzeichnung kommt dabei eine besondere ikonoklastische Kompetenz zu, denn in der Aufnahme der Verkehrsströme verschwindet der ,Held“ Bruno. Seine individuelle, dem Genre des Spionagefilms verpflichtete Aktion wird überschrieben von den mechanisierten, durch Ampelanlagen strukturierten Strömen der Passanten und Autos. Sie sind es, die die Titelfragen „Woher? Wo? Wohin?“ dokumentieren, während sie der Logik der Spielhandlung einen ephemeren Platz zuweisen. Dramatischromantische Klaviermusik unterstreicht die emphatische Aussage, dass dieses eigentlich dokumentarische Bild einer Verkehrskreuzung den ästhetischen als gestimmten Raum in seiner utopischen Qualität meint. Nur anfänglich scheint ihm die Funktion eines establishing shot zuzukommen, die im Verlauf der Einstellung jedoch revidiert wird. Der Aufblick in den Himmel bedeutet - wenn auch temporär - den Ausstieg aus der Narration, die Arretierung des Bildes.

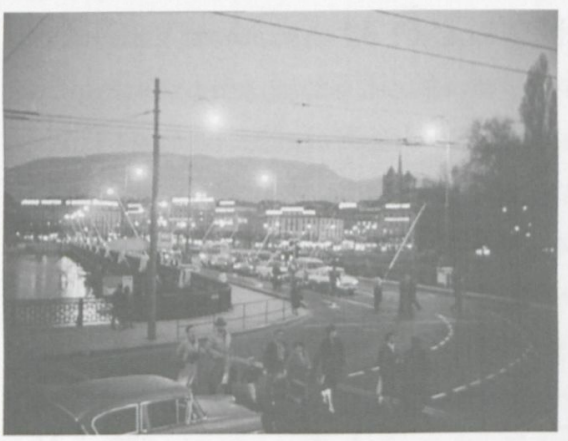

Abb. 1: Jean-Luc Godard: Le Petit Soldat (1960). Ankunft in Genf (Screenshot).

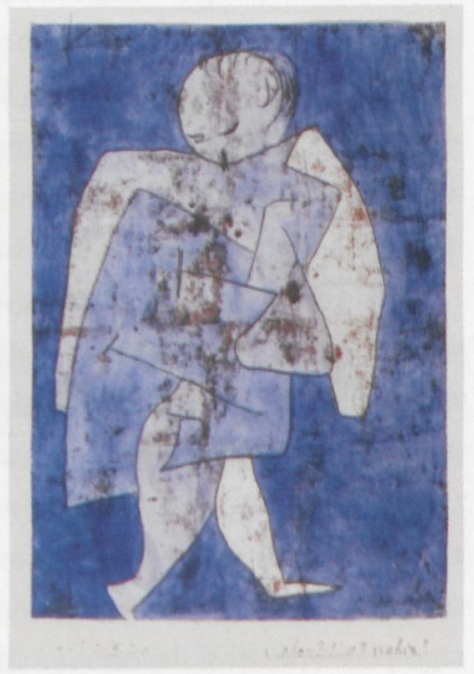

Abb. 2: Paul Klee: Woher? Wo? Wobin? Eidola, 1940, 60 (X 20), Privatbesitz Schweiz. Aquarell, Rötel und Kreide auf Papier auf Karton, 29,7 x 20,8 cm. Aus: Catalogue Raisonné. Hg. v. der Paul-Klee-Stiftung, Kunstmuseum Bern. Bern: Benteli, 2004, Bd. 9, Nr. 9079, 69 . 
24 Zum politischen Kontext ausführlich Brody (2008), 81-105.
Durch die folgende diskontinuierliche Überleitung zur Tageslicht-Nahaufnahme einer Ansichtskarten-Reproduktion des Werks von Klee artikuliert Godard den Paragone mit der Malerei ganz deutlich. Klees Bild, das zunächst als verbal evoziertes Vorstellungsbild in der Erzählung des Off-Sprechers existiert, erscheint entgegen jeder narrativen Logik - in Gestalt der Kunstpostkarte, die Bruno an einem Zeitungs-Kiosk erwirbt als konkretes Objekt im diegetischen Raum, der sich gleichwohl nicht als ,reiner' Handlungsraum definieren lässt, da die metafilmische Argumentation fortgesetzt wird. Demonstrativ führt der Kiosk die Macht der massenmedialen Wirklichkeitskonstruktion als Kontext, ja als Bedingungsrahmen des Kunstbildes (und somit auch des Films) vor. Zudem dokumentieren die die Spielhandlung begleitenden Zeitungs- und Radionachrichten die Realität des Algerienkrieges und des Krieges der Geheimdienste. ${ }^{24}$ Godards ästhetische Kritik an der Genrelogik zeigt sehr viel deutlicher als in $\grave{A}$ bout de souffle ihre Affinität zu dem Versuch des Protagonisten, sich aus den Zwängen seiner gesellschaftlichen Rolle zu befreien, deren Logik sich als opak erweist: Vergeblich wird sich Bruno am Ende für den Lohn zweier Tickets nach Brasilien zur Ausführung des Mordes entschließen, denn Veronica, Agentin der Gegenseite, ist von seinen Auftraggebern bereits getötet worden. Godard hat offensichtlich das brisante, die Zensur auf den Plan rufende politische Thema gewählt, um die Verflochtenheit konventioneller filmischer Form mit der schlechten Wirklichkeit empfindlich spürbar zu machen.

Auch insofern folgt Godard Benjamins Konzept der Aura-Krise, wenn er nicht nur die Vision der Kunst, sondern auch die der Liebe, als analog gedachte postreligiöse Sphäre eines authentischen Lebens, durch die technisch-apparative Vermittlung und die ihr inhärenten gesellschaftlichen Normen bricht. Ebenfalls in der Kiosk-Szene wird diese immer wieder programmatische Engführung von Kunst und Liebe zum Thema. Brunos Bekannter Hugo erzählt von einem Mädchen, das ,schöner ‘ als das Bild Klees sei. Und er misst die Schönheit jenes Mädchens an der des Filmstars, hat sie doch, so Hugo, einen Mund wie (der MusicalStar) Leslie Caron. Bruno dagegen wird in ihr eher eine (Klees Kunst adäquate) Vertreterin der Hochkunst sehen. Seinem eigenen Bericht nach erschien sie ihm bei ihrem ersten Zusammentreffen wie eine Figur aus einem Stück von Jean Giraudoux. Der Bildstatus der Frau, ob dem einer Theaterschauspielerin oder einem Kinostar nachgebildet, macht dem des Himmels Konkurrenz bei der Verheißung des „wahren Lebens“, worauf der Name Veronica (vera icon) überdeutlich verweist. 
Eine Einstellungsfolge widmet sich explizit der metaphorischen Nähe zwischen nächtlichem Dunkel und rätselhafter Weiblichkeit. Nach seiner Weigerung dem Mordbefehl nachzukommen, die ihn im System des Spionagefilms notwendig zum Verfolgten macht, hat Bruno vergeblich mit der brasilianischen Botschaft telefoniert, um ein Flugticket für sich und Veronica zu erfragen. Die entsprechende Einstellung zeigt ihn von außen - in einem erleuchteten Innenraum, hinter verschachtelten, spiegelnden Glasscheiben, die seine Person in einem abstrakt-funktionalistischen Architekturgerüst fast zum Verschwinden bringen. Auf diese von der Kamera inszenierte Optik eines nicht-sehenden Sehens folgt die subjektive Erfahrung eines sich der Sichtbarkeit entziehenden Raums, dargestellt durch den Blick aus einem fahrenden Auto in den Himmel und kommentiert durch die Off-Stimme Brunos:

Dann bin ich durch die Stadt gefabren. Die Silhouetten der Häuser vor dem Sternenhimmel haben für mich immer etwas Ergreifendes. Gleichzeitig hart und voller Geheimnisse seben sie aus, so wie Menschen und das, was hinter ibnen steht.

Es folgt eine Großaufnahme Veronicas, deren Blick ins Off nach links vielleicht anzeigt, dass sie den Vorüberfahrenden erkannt hat. Bruno jedoch hält aus „Angst“ nicht an. Er muss „ein paar Haken schlagen“, um seinen Verfolger abzuhängen. Seine Rede endet mit den Worten: „Alles schweigt. Der Feind ruht sich im Schatten aus." Damit antizipiert die Sequenz bereits den gesamten Film. Bruno entkommt dem Mordauftrag nicht und verfehlt auch ein Leben mit Veronica, die am Ende den Foltertod erleidet. Was ihm nach der lapidar mitgeteilten Nachricht bleibt, ist die Erleichterung über die ihm noch offen stehende Zukunft. Das lakonische Resümee des Off-Erzählers Bruno vermeidet auf geradezu drastische Weise eine Ausmalung des tragischen Endes und jeden Hinweis auf eine emotionale Reaktion. Während der HollywoodKlassiker vorgibt, den emotionalen Impuls des Akteurs in einer in sich notwendigen Handlung zu entfalten, ist bei Godard das Subjekt immer das Subjekt ästhetischer Erfahrung jenseits der Handlungslogik.

Die in $A$ bout de souffle und Le Petit Soldat entwickelte Spannung zwischen dem emphatisch erlebten „dunklen Blau“ des Himmels in der Abenddämmerung und dem (hier noch) genrebezogenen Handlungszwang wird in den nächsten Filmen immer wieder neu formuliert. Der gestimmte Raum dementiert jeweils den physiognomischen Mythos der Form als Ausdruck. Gefühl erscheint nicht als partielles, im Modus der Handlung sich Ausdruck verschaffendes, sondern als Widerspruch gegen 
25 Zum Bild der Dämmerung vgl. Böhme (1999), 95-109.

26 Anzuknüpfen ist vor allem an einige Deutungsperspektiven bei Bersani/Dutoit (2003), den antipsychologischen Gehalt der Filmerzählung betreffend. Weitere Analysen zu Le Mépris u. a. bei Coates (1988), Aumont (1990), Kilb (1990), Vimenet (1991), Schleicher (1991) und Cerisuelo (2006). sie, als Verneinung von repräsentativer Sichtbarkeit, als Stimmung. Ihre Erfahrung ist die von Bezüglichkeit, von Raum; und sie steigert sich von kontemplativer Emphase zu ekstatischer Euphorie. Neben dem Bild der Dämmerung und der Nacht, das eine Totalitätserfahrung an das Verschwinden von Farbe und Licht knüpft ${ }^{25}$, thematisierte Godard auch immer häufiger den Blick in den mittäglichen Himmel, dessen euphorische Auflösung der narrativen Logik Michel in À bout de souffle bereits vorgegeben hat. Wiederkehr und Variation dieser atmosphärischen Negierung des Kommerzkinos im Bild des Himmels lassen sich insbesondere an einigen jener Filme studieren, die das Thema der heterosexuellen Paarbeziehung mit der Reflexion auf ästhetische Erfahrung in ihren Facetten der Schaulust und des Glücksstrebens verbinden.

\section{Kritik der Romanze: Von Le Mépris zu Pierrot le fou}

In Le Mépris, dem zweiten Farbfilm Godards, hat der blaue Himmel, im Verbund mit der ebenso blauen Meeresfläche, eine zentrale metafilmische Bedeutung, die in den zahlreichen Kommentaren zu diesem Filmwerk deshalb nicht thematisch wurde, weil diese sich weitgehend, trotz der grundsätzlichen Einsicht in die autoreflexive Filmästhetik Godards, weniger auf die Form als auf die Handlung beziehen. ${ }^{26}$ Der hier vorgelegte Kommentar geht explizit von der Eigenleistung des filmischen Bildes bei Godard aus und kommt auf diesem Weg auch zu einer neuen Lesart der Handlung.

Die von touristischen Stimmungswerten entbundene hochsommerliche Landschaft Capris korrespondiert in der verblichenen, substanzauflösenden Helligkeit mit dem undurchdringlichen Gefühl der Verachtung, welche Camille (Brigitte Bardot) plötzlich ihrem Ehemann Paul Javal (Michel Piccoli) entgegenbringt. Anders als in der literarischen Vorlage, Alberto Moravias Roman Il disprezzo (1954), und anders als in dem ebenfalls zitierten Film Il Viaggio in Italia (1958) von Roberto Rossellini steht nicht das eheliche Zerwürfnis als solches im Zentrum. Vielmehr ist die Liebe und ihr von Camille beklagter Verlust nur ein anderer Ausdruck für die (Film-)Kunst und ihre Zerrüttung, an der Paul sich mitschuldig zu machen droht. Nicht um eine Literaturverfilmung oder ein Remake geht es, auch nicht um eine Replik auf bestimmte filmische Genreformen. Vielmehr ist der griechische Mythos Gegenstand eines komplexen Spiels der Adaptionen und Identifikationen. Die Insel Capri ist Drehort eines Films über Homers Odyssee. Sein Regisseur ist Fritz Lang (von ihm selbst 
verkörpert), dessen Drehbuch Paul, im Auftrag des Produzenten Jeremy Prokosch (Jack Palance), marktgerecht verändern soll, da die künstlerischen Ambitionen Langs den kommerziellen Erfolg gefährden. Schon dadurch, dass Godard selbst in die Rolle von Langs Assistenten schlüpft, macht er seine Parteinahme klar. Lang verkörpert das „Gewissen“ der Filmkunst und ihren Widerstand gegen die kunstfremde Autorität des Produzenten $^{27}$, einen Kampf, der wiederum gespiegelt wird im Kampf des Odysseus gegen die ihm feindlich gesinnten Götter, insbesondere Poseidon. Aber auch Paul ist ein (eher unwillig akzeptiertes) Alter Ego Godards, in seiner Ambivalenz zwischen dem Wunsch, durch die Realisierung des Auftrags aller Geldsorgen ledig zu sein, und seiner ,eigentlichen' Berufung als Theaterschriftsteller. Parallel zu jener Konkurrenz zwischen trivialer und, ernster ${ }^{`}$ Kunst gibt es zwei rivalisierende Auslegungen des Mythos. Lang und auch Camille vertreten die jeder psychologischen Deutung abholde Einfachheit und Unmittelbarkeit der Intentionen und Handlungsweisen des Odysseus, während Paul sich dem Wunsch des Produzenten anpasst, den Mythos zu modernisieren und Odysseus als „modernen Neurotiker“ (Lang) zu interpretieren, der deshalb so lange in der Ferne weilte, weil seine Ehe mit Penelope in der Krise steckte. Gegen diese, von Moravias Novelle nur vorgeblich aufgekündigte Psychologisierung des Mythos im Sinne des modernen, bereits von Proust zu Grabe getragenen psychologischen Romans wendet sich die brechtische Ästhetik von Godards Film. ${ }^{28}$ In einer Einstellung der Appartement-Sequenz trägt Paul ein Badehandtuch wie eine Toga um die Schulter drapiert, Anspielung auf seine tragische Rolle, die nicht ursächlich psychische, sondern konkret materiell-gesellschaftliche Gründe hat. Der unauflösliche, gleichwohl von den Akteuren nicht bewusst eingesehene Konflikt besteht darin, dass Paul weder das eine noch das andere tun kann. Erfüllt er seinen Vertrag, verliert er vollends die Achtung Camilles, die ihm unterschwellig vorwirft, sich und sie für den Auftrag zu prostituieren, scheint er sie doch in die Arme Prokoschs zu treiben. Erfüllt Paul den Auftrag nicht, kann er die gemeinsame Wohnung nicht bezahlen und Camilles Wünschen nicht gerecht werden. Aus diesem Dilemma führt nur der gemeinsame Unfalltod von Camille und Prokosch heraus, der, was die bislang zu stark handlungsorientierten Interpreten nicht erkannten, von Camille selbst verursacht wurde. Dafür sprechen folgende Indizien: Auf die Frage Prokoschs, der an einer näheren Beziehung interessiert ist, was sie von ihm halte, lauten ihre (letzten) Worte: „Steigen sie in Ihren Alfa Romeo. Das sehen wir später.“ Dass

$27 \mathrm{Vgl}$. Godard in dem von Yvonne Baby geführten Interview: Baby (1972), $38 \mathrm{f}$.

28 Zur nicht eingelösten Kritik der (schon von Proust aufgekündigten) Konvention des psychologischen Romans durch Moravia vgl. Bersani/Dutoit (2003), $4 \mathrm{ff}$. Zum Verhältnis von literarischer Vorlage und Film vgl. auch Kinder (1981). 
$29 \mathrm{Vgl}$. Abb. und Beschreibung bei Marie (2006), 196.

Camille zudem durch ihr schriftliches „Adieu“ an Paul ihren Tod ankündigte, wird durch die Montagesequenz verdeutlicht, die die Aufnahmen des Unfallautos mit dem Abschiedsbrief Camilles kombiniert. ${ }^{29}$ Camille ist demnach im Spiegel des Mythos nicht nur Penelope, die Ehefrau des Helden Odysseus, sondern auch Athena-Minerva, seine Beschützerin, Vertreterin eines idealen Kollektivs, das nur von der Filmkunst antizipiert, nicht jedoch in der Ehe gelebt werden kann, die notwendig durch gesellschaftliche Zwänge versehrt ist. Durch Camilles und Prokoschs Tod ist dafür gesorgt, dass Paul seiner Berufung als Theaterschriftsteller folgen und Fritz Lang seinen Film zu Ende drehen kann. Diese erneute Öffnung des filmischen Raums ist Thema der Schlusseinstellung des Films, die als Replik auf die im Folgenden kommentierte erste Einstellung noch darzustellen sein wird.

In der Trailersequenz, die einen sonnenverbrannten Platz in Cinecittà zeigt, feiert der mittäglich blaue Himmel seinen ersten majestätischen Auftritt. Aus der Untersicht erfasst, gleitet von ferne auf Schienen eine gigantische Mitchell-Kamera heran, bedient von Godards Kameramann Raoul Coutard selbst, der Francesca, die Assistentin des Produzenten, in einer Begleitfahrt aufnimmt, während sie in einem Manuskript blättert. Am Ende der Fahrt schwenkt die Kamera um $90^{\circ}$ und richtet ihre Linse nach unten, so dass wir, das Publikum, direkt anvisiert werden (Abb. 3b). Dazu ertönt aus dem Off eine Erklärung des Films: „Das Kino, sagte Bazin, schafft für unseren Blick eine Welt, die auf unser Begehren zugeschnitten ist. Le Mépris ist die Geschichte dieser Welt."

Durch die Neigung der Kamera und ihre

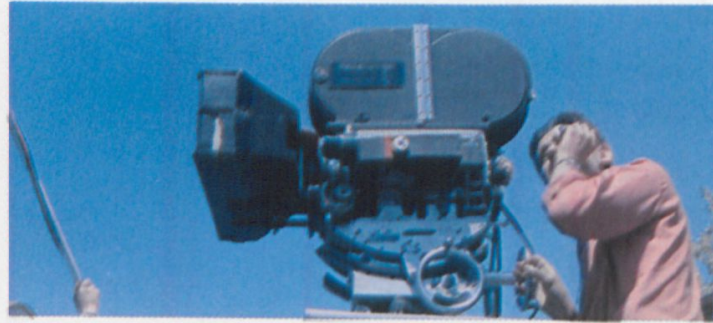

Abb. 3a: Jean-Luc Godard: Le Mépris (1962). Prolog: Coutard an der Kamera (Screenshot). Isolierung vor dem abstrakten Blau des Himmels wird sie als ein anthropomorphes Wesen definiert, das sich ,uns ${ }^{6}$ zuwendet, während es eine Welt konstruiert, die ,unseren' Wünschen gehorcht, deren Urheber also eigentlich, wir ${ }^{`}$ sind. Hierauf scheint auch der spätere, von Lang ausgesprochene Satz anzuspielen, dass nicht die Götter die Menschen, sondern diese die Götter geschaffen haben. Doch das Verhältnis des Bildes zum Text ist komplizierter. Gezeigt wird ein Raum, dessen ontologischer Status ungewiss ist. Zunächst scheinen wir in die Lage versetzt, die Produktion des Films Le Mépris zu beobachten, als unbeteiligte, unsichtbare Zuschauer. In diesem Zeitabschnitt erscheint 
der Einstellungsraum im Sinne der klassischen Tradition als geschlossener fiktionaler Raum, obgleich wir uns noch nicht in der Diegese befinden, sondern noch innerhalb des visuell-auditiven Rahmens, der die Herstellung des Films dokumentiert. Durch die überraschende Wendung ins Off nach vorn wird diese ästhetische Grenze gesprengt, der Realraum zum Thema gemacht, denn durch den Schwenk stellt die Kamera Coutards ihre Aufgabe in Frage, eine diegetische Welt zu

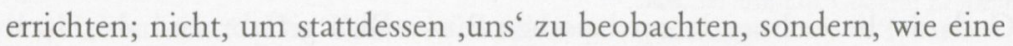
weniger naive Einstellung bewusst macht, um die vermeintlich neutrale Kameraposition in den Blick zu nehmen, die uns die Illusion einer unmittelbaren Zeugenschaft erlaubt. Godard demonstriert also seine programmatische Aufspaltung der filmischen Arbeit in die Konstruktion einer fiktional-diegetischen Welt und deren Dekonstruktion. ${ }^{30}$ Der klare blaue Himmel überspannt beide Räume, den narrativen wie den reflexiven, Natur und Kunst. Ein bislang übersehenes Detail unterstreicht diese Bedeutung. Kurz bevor Coutard die Kurbel betätigt und zum Schwenk ansetzt, zückt er eine Linse, durch die hindurch er nach vorn oben ins Licht blickt, so als müsse er Belichtungswerte messen (Abb.3a). Ein rein technischer Vorgang ist aber sicher nicht gemeint. Der dem Kamerablick nach unten vorausgehende Blick nach oben markiert vielmehr, zeitlich genau mit dem Bazin-Zitat der ,nach unseren Wünschen erschaffenen filmischen Welt zusammenfallend, den Himmelsraum als utopischen Raum. In Fritz Langs Verfilmung der Odyssee hinterfängt er Büsten antiker Statuen, die gleichsam den Blick der Kamera wieder aufnehmen. Insbesondere Minerva ist hier zu nennen, denn sie wiederholt in ihrer majestätischen Drehung aus dem Profil um $90^{\circ}$ nach vorn (Abb. $3 \mathrm{c}$ und $3 \mathrm{~d}$ ) zuletzt genau den Schwenk der Kamera Coutards zu Beginn. Paul, der im Vorführraum diese Einstellung aus Langs Film betrachtet,
30 Dass diese Negation des diegetischen Raums dem Medium des Films bereits inhärent ist, deutet sich schon in Souriaus elementarer Unterscheidung von diegetischem und leinwandlichem, durch den rektangulären Rahmen bestimmten Raum an. Vgl. Souriau (1951).

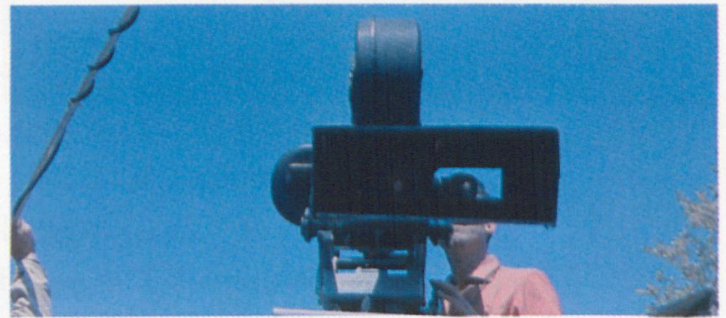

Abb. 3b: Jean-Luc Godard: Le Mépris (1962). Prolog: Coutard an der Kamera (Screenshot).

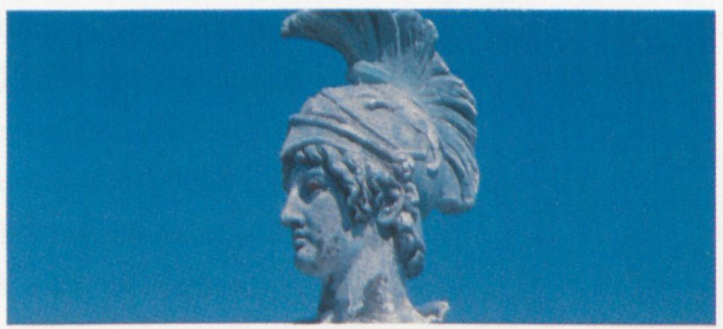

Abb. 3c: Jean-Luc Godard: Le Mépris (1962). Minerva (Screenshot).

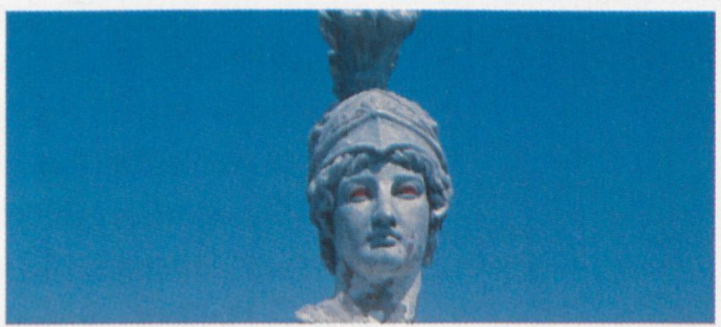

Abb. 3d: Jean-Luc Godard: Le Mépris (1962). Minerva (Screenshot). 
31 Später, wenn Paul und Camille vom Besuch bei Prokosch nach Hause zurückkehren, folgt erneut ein ,Schwenk der Minerva-Büste. Gleich darauf liest Paul das Kinoprogramm aus der Zeitung vor.

$32 \mathrm{Vgl}$. die „kristallblauen Himmel" und „Blutgeruch in der Luft" verdichtende Metaphorik in Bande à part (1964). ,erwidert ${ }^{\star}$ ihren Blick, bestätigt also die besondere, oben begründete Beziehung zu ,seiner ${ }^{6}$ Schutzgöttin. ${ }^{31}$ Deren rotgefärbte Augenhöhlen versinnbildlichen bereits das Opfer für die Kunst, indem sie auf eine favorisierte Farbe Camilles, das Sofa der ehelichen Wohnung und den Alfa Romeo anspielen. Das Blutrot der Augen Minervas wiederum ergänzen die blauen Augenhöhlen der zuerst gezeigten, mit dem Namen Odysseus verbundenen und mithin das mythische Alter Ego Pauls (und Godards) bezeichnenden archaischen Büste. Blau gefärbt sind aber auch Mund und Augenhöhlen Neptuns, des mythischen Spiegelbildes Prokoschs. Auch hier wiederholt sich also der ,Blick' von Coutards Kamera, in dem sich gleichsam das Himmelsblau sammelte und Subjekt wurde. Der mythische Held und die Götter repräsentieren den geöffneten, seine historischen Konstruktionsmuster aufdeckenden filmischen Raum. Ihr Blick aus leeren, farbig gefüllten Augenhöhlen ist nicht der Blick einer Person, sondern der Blick eines idealen Kollektivs. Blutiges Rot und kristallines Blau sind seine am Himmel erscheinenden Farben (zuzüglich des Sonnengelbs, das in den Bademänteln Camilles und Francescas erscheint). ${ }^{32}$ Dass sowohl dem Produzenten als auch dem revolutionären Künstlersubjekt Odysseus-Paul-Godard das euphorische Blau des mittäglichen Himmels zugeordnet wird, lässt sich auf die dialektische Einsicht in die Avanciertheit der industriellen Produktionsform zurückführen, die Godard bekanntlich für das amerikanische Kommerzkino eingenommen hat. Der Blick der Kamera wie der Statuen ins Off nach vorn ist kein subjektiver, sondern Vorschein einer der ästhetischen Grenze nicht mehr bedürftigen idealen Gesellschaft.

Die Schlusseinstellung bekräftigt den durch Prokoschs Tod möglichen Sieg einer revolutionären Filmästhetik, indem sie an das erste Bild wieder anschließt, nicht zuletzt durch den erneuten Kamerablick aus dem Bild, der hier allerdings, wie während einer vergleichbaren früheren Einstellung auf dem Filmboot, der innerdiegetischen Kamera Fritz Langs gehört. Auf dem Dach der Villa Malaparte, zu dem eine Art gigantische Himmelstreppe führt, ist Langs Filmteam versammelt, einschließlich des Assistenten Godard. Fast gleichzeitig mit Paul betritt er, ähnlich bekleidet, die Szene. Der zunächst statische Aufnahmewinkel ist so gewählt, dass Godard immer wieder hinter Lang verschwindet, während dieser sich von Paul verabschiedet. Als Lang seinen Regiestuhl verlässt, stellt Godard sich im Hintergrund so auf, dass er gleichsam auf der Lehne zu stehen scheint (Abb. 3e). Trotz dieser visuellen und auch auditiven Solidaritätsbekundungen Godards, der schließlich aktive Kommandos gibt für die 
Aufnahme von Odysseus' Heimkehr, kann von einer Übereinkunft zwischen seinem und Langs Film nicht die Rede sein. ${ }^{33}$ Zwar zoomt und schwenkt die Kamera Coutards in Richtung der innerdiegetischen Kamerafahrt des Lang-Teams, welche nunmehr mit Blick auf das Meer die stilisierte Aktion des Helden filmt. Die Kameraperspektive bleibt jedoch deutlich eine andere, auch wenn sie die Passierfahrt nach links adaptiert. Schon die Interpretation von Odysseus' Blick auf Ithaka (Abb. 3f), nicht erst die folgende Entleerung des Bildes, artikuliert den Ausstieg aus der Narration. Die von Godard gefilmte Begleitfahrt der Kamera Langs richtet sich hier nicht, wie im Prolog die Kamera Coutards, auf ein

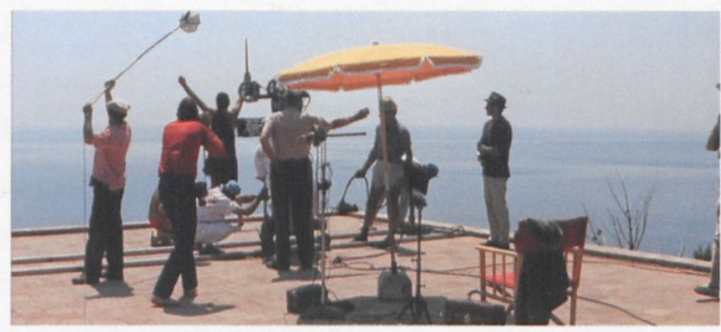

Abb. 3e: Jean-Luc Godard: Le Mépris (1962). Fritz Langs Filmteam (Screenshot).

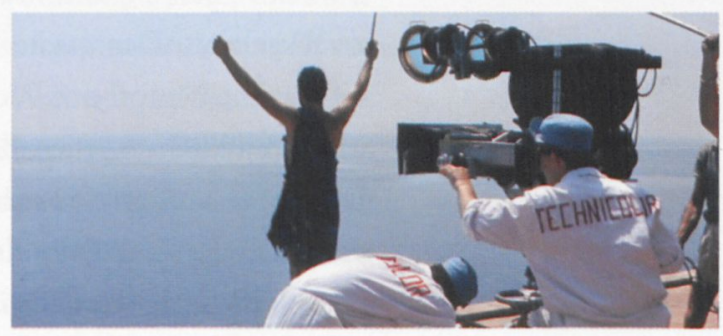

Abb. 3f: Jean-Luc Godard: Le Mépris (1962). Odysseus kehrt nach Ithaka heim (Screenshot). realistisches Agieren, obwohl der Odysseus verkörpernde Schauspieler in Kleidung und Habitus dem filmischen Genre des antiken Historiendramas entspricht. Wie die romantische Rückenfigur kann er sich jedoch nicht in den Raum hineinbewegen, sondern verharrt in einer vorderen Raumschicht. ${ }^{34}$ Auch fehlt jeder sinnfällige expressive Ausdruck der Freude über den Anblick der heimatlichen Küste. Vielmehr schreitet Odysseus langsam, mit starr emporgereckten Armen, entlang der bildparallel verlaufenden Schienen, als sei er mit der Apparatur gleichgeschaltet. Die steinerne Dachterrasse der Villa, wie ein bizarres Aussichtsplateau zugleich hoch erhoben über die Landschaft und abgeschnitten von ihr, intensiviert den Eindruck einer unüberschreitbaren Grenze. ${ }^{35}$ Der Figur kommt kein Handlungsraum $\mathrm{zu}$, sie verfügt nicht über eigene Impulse. Deutlich hat Godard in der Rolle des Regieassistenten zuvor ihre Aufstellung kontrolliert, was ihren metafilmischen, an die Bühnenmetaphorik der Dachterrasse anknüpfenden Sinn unterstreicht. ${ }^{36}$ Die hochgereckt ausgebreiteten Arme des Odysseus lassen sich als ein theatralisch künstliches Zeichen des Grußes an die Heimat lesen. Darüber hinaus wirkt das Schwert geradezu wie ein Taktstock, kommt die Positionierung des Odysseus der Aufstellung eines Dirigenten gleich, der das Orchester zur Sammlung ruft und gleich den Einsatz für das nächste Stück geben wird. ${ }^{37}$ In diesem Sinne wird tatsächlich der Raum geöffnet. Die Kamera Coutards verlässt die Figur, um

$33 \mathrm{Zu}$ seiner durchaus distanzierten Einschätzung Langs vgl. Godard (1992), $84 \mathrm{f}$.

$34 \mathrm{Vgl}$. die frühere, in das Gespräch mit Lang eingefügte Aufnahme Pauls, der, starr auf einem Felsen stehend und sich am Gebüsch festklammernd, auf das weite Meer blickt. Abb. bei Cerisuelo (2006), 67.

35 Zur Flächenbindung der romantischen Rückenfigur vgl. Prange (2010a), $147 \mathrm{ff}$. Zur Begründung der "ewigen Heimat" der Liebenden nach Binswanger vgl. Bollnow (1963), 264-268.

36 Vgl. hierzu Bersani/ Dutoit (2003), $12 \mathrm{f}$.

37 Vgl. das Ende von Bande à part, das mit Blick auf das Meer die Fortsetzung der Geschichte im Sinne eines Hintertreppenromans verspricht. 
Abb. 3g: Jean-Luc Godard: Le Mépris (1962). Schlusseinstellung (Screenshot). in fortgesetzter Fahrt nur noch Meer und Himmel zu zeigen (Abb.3g) - Wiederholung und Variation zweier früherer Totalen. Der erste isolierte Meerblick stammt aus Langs Filmpräsentation. Er folgt, eingeleitet durch Klappenschlag, auf Odysseus' Ersteigung eines Felsens in Ufernähe und wird im Laufe der Einstellung in die Bucht und damit potentiell in die Narration zurückgeleitet. Der zweite Meerblick erzählt, wie Prokosch mit Camille auf seinem Motorboot Richtung Horizont rast und verschwindet. Das Schlussbild kommentiert diese vorangegangenen Einstellungen. Die keinerlei Spur von menschlicher Aktion mehr aufweisende Meeresfläche ist gleichsam das Grab Camilles und Prokoschs. Rufe aus dem Off („Silence! Silenzio!") beziehen den narrativen Raum des Films im Film zwar noch ein, implizieren aber zugleich seine Umdeutung zum Epitaph. In der abstrakten Erscheinung von Meer und Himmel wird ein unendlich erweiterter filmischer Raum präsentiert, der zwar an Langs episches Maß anknüpft, der Erzählung von Göttern und Helden aber nicht bedarf, haben sich diese doch als Figurationen des Kamerablicks erwiesen. Der höher gelegte, leicht sphärisch gekrümmte Horizont postuliert gegenüber Langs Vision einen kosmisch universalen Standort. Wo Langs Kamera wieder ans Ufer zurückschwenkt, zeigt Godards/Coutards Kamera die umgekehrte Bewegung vom geschlossenen in den offenen Raum. Der zu Beginn der Einstellung noch erahnbare Küstenstreifen - Ithaka - verschwindet. Das am Filmende gewöhnlich gegebene Versprechen ,anzukommen' wird entzogen und zugleich durch ein größeres Ziel ersetzt.

„Wie im Kino. Der Himmel ist blau.“ Dieser von Charlotte (Macha Méril) in Une femme mariée geflüsterte Kommentar verdichtet die kinematografische Verheißung des filmischen als euphorischen Raums in einer poetisch lapidaren Formel, deren Geltungsmacht Godard immer wieder beschwört und befragt. Während in Le Mépris die Produktion und mythische Wurzel jenes ,nach unseren Wünschen' gestalteten Raums zur Debatte stand, reflektiert der Schwarz-Weiß-Film Une femme mariée eher die Seite der Rezeption in ihrem alltäglichen Gebrauchswert. Das amouröse Abenteuer der weiblichen Heldin wird mit dem Gang ins Kino vergleichbar, wo sie sich mit ihrem Liebhaber Robert (Bernard Noël) trifft, bezeichnenderweise im Flugplatzgebäude von Orly, wodurch die Flucht aus dem geschlossenen Raum (des Genres wie 
der gesellschaftlichen Institutionen, hier der Ehe) markiert wird. (Dass auch Charlottes Mann als Pilot mit jenem ,offenen Raum ' in Verbindung steht, mag ihn als gleichwertigen Konkurrenten des Liebhabers ausweisen; Godard unterläuft auch hier die übliche klischeehafte Kontrastbildung.) Der zitierte Text gehört zu dem durchweg geflüsterten, vermeintlich Intimität ausstellenden voice over-Kommentar, der jedoch lediglich Bruchstücke von Gedanken und Erfahrungen aneinanderreiht, die keinerlei Einblick in das Innenleben der Heldin erlauben. Er begleitet hier Aufnahmen einer ausgelassenen Schwimmbad-Szene, die kurz darauf ins Negativ transformiert werden und somit, im Widerspruch zu der beschworenen idealen Natur des blauen Himmels im Kino, ihren Materialcharakter vorweisen. Das schöne Wetter im Hollywood-Film, den Charlotte ausdrücklich über den italienischen Neorealismus stellt, wird beiläufig als Maßstab eines alltäglichen Glücks in den Dienst genommen und mit der unheimlichen Opazität des Negativfilms kontrastiert. Ähnlich stand für Bruno in Le Petit Soldat das in einem Werk Klees aufgefundene „tiefe Blau des Himmels“ für eine vitale Daseinserfahrung jenseits alltäglicher Partikularität, aber auch für die Undurchdringlichkeit des Anderen gerade in der erotischen Begegnung. Auch Charlottes Flucht vor den Spitzeln ihres Mannes richtet sich auf eine ästhetische Sphäre, was u. a. durch den Schauspielerberuf des Geliebten manifest wird. Ihre Suche nach einem Leben in der Gegenwart, das dem männlichen Geschichts- und Zukunftsdenken gegenübergestellt wird, erscheint mit der Perspektive der Filmzuschauerin gekoppelt. Dies zeigt explizit eine Einstellung, in der sie mit Robert in seinem Auto die Seine entlang in Richtung Eiffelturm unterwegs ist. Auf dessen Ermahnung, sich auf dem Beifahrersitz nicht länger zu verstecken und eine normale Sitzposition einzunehmen, bemerkt sie, ihre Haltung entspreche in idealer Weise der Position im Kinosessel. Halb liegend, einem Embryo gleich die Beine angezogen, blättert sie im France Soir. Die leichte Untersicht sorgt dafür, dass nicht das in Rückansicht aufgenommene Paar zentriert wird, sondern die weite indifferente Fläche des Himmels, welche somit gleichsam die auf Charlottes Sitzposition bezogene Rolle der Leinwand einnimmt. ${ }^{38}$ Ähnliche Perspektiven und Wirkungen werden im Übrigen bei den ausgedehnten Autofahrten in Bande à part

38 Protokoll und Abb. bei Godard (1966), 23 f. gestaltet, die somit unterschwellig ebenfalls jener Identifizierung des Himmels mit der Kino-Leinwand huldigen, die Figuren grundsätzlich aus der Geschlossenheit des Erzählraums entbinden, indem sie sie als Betrachter definieren. 
39 Zum kompilatorischen Charakter von Pierrot le fou und der Tradition romantischer Utopie vgl. v. a. Pantenburg (2006), 88-107. Weitere Kommentare in: Barr (1969), 94-107, Godard (1979), 138 f., Vacche (1995), Wills (2000) und Engell (2003).
Die über jene Zitierweisen des Kinohimmels hinausgehende Modellierung einer alternativen Filmästhetik mithilfe der Himmelsschau wird in dem als Bilanz des Frühwerks geltenden Film Pierrot le fou wieder relevant. ${ }^{39}$ Exemplarisch markiert schon der Prolog nicht nur die programmatische Zitatform, sondern auch die mit dem Himmelsmotiv aufgerufene ästhetische Struktur einer , anderen' filmischen Form. Zu unheilschwangeren symphonischen Mollklängen und gleichzeitig mit dem in blauer Schrift erscheinenden - und bis auf die Nullform des „O“ wieder verschwindenden - Titel Pierrot le fou spricht eine männliche Stimme aus dem Off: „Velázquez hat in seinem 50. Lebensjahr eine neue Ausdrucksweise gefunden." Dabei erscheinen Total- und Halbnah-Aufnahmen einer brünetten, hell gekleideten jungen Frau beim Tennisspiel im sonnendurchfluteten Jardin des Tuileries, während der Sprecher aus dem Off seine Rede fortsetzt:

Alle Dinge, die er malte, umgab er mit Luft und Dämmerung. Überraschend die Schatten und die Transparenz der Hintergründe, die farbigen Reflexe, die er zum unsichtbaren Mittelpunkt seiner Kompositionen machte. Er erfasste in der Welt nur noch die geheimnisvollen Veränderungen. An dieser Stelle führt eine Totale den Protagonisten Ferdinand (Jean-Paul Belmondo) ein, der ebenfalls von hellem Sonnenlicht bestrahlt vor einer Buchhandlung steht und die Auslage betrachtet, einen Stapel Bücher im Arm. Über ihm erscheint auf einem Werbetransparent in monumentalen, das Licht reflektierenden roten Lettern die an Leibniz' Rede von der ,besten aller Welten' erinnernde Botschaft „Le meilleur des mondes“. Während Ferdinand, versunken in die Betrachtung der ausgestellten Bücher zunächst eines der Gestelle in Drehung versetzt, sich dann dem nächsten zuwendet, dieses ebenfalls dreht und ein Buch entnimmt, spricht die Stimme weiter:

Veränderungen, die Formen und Töne einander durchdringen lassen in einem unaufhörlichen Fließen, bei dem kein Stoß, kein Ruck die Bewegung stört oder unterbricht. Der Raum nun allein regiert.

Beim letzten Satz verschwindet Ferdinand mit seiner Buchauswahl im dunklen Innenraum des Ladens und es folgt, untermalt von einer neuen verheißungsvoll sich aufschwingenden Melodie, das Panorama einer romantischen Abendlandschaft. Ein rötlicher Schimmer liegt über dem Horizont. Lichter von Straßenlaternen lassen schwach den Verlauf einer Straße über eine Brücke erahnen, während zwei vertikale Lichtbahnen im Vordergrund eine leicht bewegte große Wasserfläche markieren. Nun folgt der letzte Teil der künstlerischen Vision des Velázquez: 
Es ist, als ob eine Luftwelle über die Dinge gleitet, sich mit ibren Ausstrablungen sättigt, um ihnen eine neue Gestalt zu verleiben. Um sie weiterzutragen wie einen Duft, wie ein Echo, wie einen unsagbar feinen

Staub, der sich auf die endlose Weite, die sie umgibt, niederlegt.

Der folgende Schnitt setzt eine harte Zäsur zwischen der bisher referierten ästhetischen Utopie und der gesellschaftlichen Realität; erst jetzt wird eindeutig ein diegetischer Raum begründet. Doch eingeführt wird in Großaufnahme des Profils nicht nur ein Filmcharakter - Ferdinand, der sich als Sprecher des Textes erweist -, sondern auch Belmondo selbst, der als Filmstar mit Zigarette im Mundwinkel posiert. Er ist Alter Ego sowohl des Malers Velázquez als auch des Regisseurs Godard. Hatte der Monolog aus dem Off als originärer Kommentar und poetische Verbindung heterogener Bilder gewirkt, erweist sich jetzt, in seiner Verwandlung zur innerdiegetischen Rede, dass er aus dem kunsthistorischen Taschenbuch von Elie Faure abgelesen wurde, also lediglich Reproduktion ist, die zudem durch den theatralischen Vortrag des Lesers in einer höchst alltäglichen Situation nun komisch-absurde Züge annimmt. Ferdinand sitzt nämlich in der Badewanne, während er mit angewiderter Miene deklamiert:

Die Welt, in der er lebte, war trostlos. Ein völlig degenerierter König, kranke und schwächliche Infanten, Geistesschwache, Zwerge, Krüppel und Irre. Dazu ein paar monströse Narren, als Prinzen verkleidet, die nur die Aufgabe hatten, über sich selbst zu lachen, um damit ibre gelangweilte Umgebung zu unterhalten. Eingeengt von der Etikette, umgeben von Falschbeit, von Komplott und Intrige.

Die nächsten Einstellungen machen diese Aussage klar übertragbar auf die mondäne bürgerliche Existenz Ferdinands, die durch Party-Glamour, Konsumzwang und Statusdünkel beherrscht scheint. Demnächst wird er, unter dem von Feuerwerk erhellten Pariser Nachthimmel, mit dem Kindermädchen Marianne Renoir (Anna Karina) die Flucht in ein anderes Leben antreten, das durch den Nachnamen seiner Geliebten als das der (Film und Malerei vereinenden) Kunst bestimmt wird. Näher besehen, ist die vermeintlich realistische Badezimmer-Szene ein Zitat, das dieses Rebellentum Ferdinands ankündigt. Denn dass die Wanne kein Wasser enthält, lässt für den (ausdrücklich eingeforderten) kunsthistorischen Blick ihren Zeichencharakter und damit den Verweis auf die Ikone des Revolutionärs, Davids Tod des Marat (1793), hervortreten. Die gelebte Utopie eines anderen Lebens scheint nicht ohne das Bild des Todes auszukommen. So kann auch Velázquez’ Malerei „des Schattens“ und des „unendlichen Raums“ als Todesmetapher, nämlich als makabre Vor- 
$40 \mathrm{Zu}$ diesem Topos vgl. Prange (1993).

41 In Je vous salue, Marie (1985) wird der „himmelnde Blick" als direkter Verweis auf religiöse Ikonografie wieder wirksam. wegnahme der Selbstsprengung Ferdinands am Ende des Films verstanden werden, die ihn gleichsam in den Raum des azurfarbenen Südens zerstäubt. Der in einer handschriftlichen Texttafel nach Art von Ferdinands Tagebuchaufzeichnungen eingefügte Kommentar - das Schriftbild „L'Art“ wird zu dem Wort „La Mort“ ergänzt - reinszeniert den Topos des (Opfer-)Tods für die Kunst bzw. der Kunst als Medium der Selbstverewigung ${ }^{40}$, allerdings unter massiv verfremdeten, ironischen Vorzeichen. Ferdinand kommt nur , aus Versehen' zu Tode, versucht er doch noch die Zündschnur zu löschen. Seine Vorbereitung auf den Suizid entbehrt jeder psychologischen Motivation und wird als eine rein theatralischrituelle Darbietung inszeniert. Schon indem er sich das Gesicht blau anstreicht, den Blick nach oben richtet und sich so der himmlischen Sphäre annähert (Abb. 4$)^{41}$, verweist er auf die Gemachtheit der finalen Ewigkeitsvision und widerspricht der Geschlossenheit des Erzählraums.

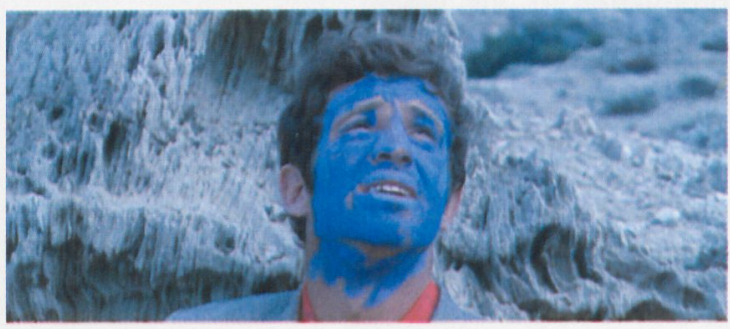

Abb. 4: Jean-Luc Godard: Pierrot le fou (1965). Ferdinand mit blau bemaltem Gesicht blickt zum Himmel (Screenshot).
Nach einer langen Passierfahrt der Kamera, die sich vom Explosionsherd wegbewegt in Richtung Sonne, bis schließlich der Horizont fast verschwindet im lichten Raum, wispern aus dem Off die Stimmen Mariannes und Ferdinands nach Versen Rimbauds, dass die „Ewigkeit wiedergefunden“ sei - „das Meer und die Sonne.“

Anders als Ferdinands Rede aus dem Off im Prolog werden diese Stimmen nicht mehr in einen diegetischen Raum überführt; das ,Jenseits', dem sie assoziativ zugewiesen sind, wird ausdrücklich verneint zugunsten der Konstatierung von Sonne und Meer als einzigen Bestandteilen der ,Ewigkeit‘. Der utopische Raum ist damit auf die physische Wirklichkeit zurückverwiesen und, ähnlich wie schon in Le Mépris, durch eine Kamerafahrt vom narrativen Raum abgezogen. Dies führt auf eine grundsätzliche Differenz: Velázquez' Malerei des atmosphärischen Zwischenraums definiert zum einen den filmischen Montageraum, zum andern wird dieser ästhetische Raum im diegetischen Raum der Romanze als subjektiver Erlebnisraum thematisiert. Ein blitzschneller Kameraschwenk nach oben artikuliert etwa das Pathos der gelebten euphorischen Stimmung in der Liebesszene am Strand, im Sinne der alten Ikonografie des Aufstiegs der Seele. Die auf den Tod Mariannes und Ferdinands folgende horizontale Kamerafahrt antwortet auf diese Exaltation, neutralisiert jede expressive Geste. Sie negiert die Höhe des Himmels, der entlang der Horizontlinie 
gleichsam in die Ebene verlegt wird, dem epischen Tempo angemessen, das auch den Anfang des Films und damit die Selbstdarstellung des filmischen Mediums bestimmt hat. So verweigert Godard am Ende die im Sinne einer Genrelogik notwendige Schließung des diegetischen Raums, um die unabschließbare Offenheit des filmischen zu manifestieren. Ästhetische Utopie und Experiment eines anderen Lebens kommen nicht überein. Die unauflösbar konflikthafte Interaktion beider Sphären ist das Thema des Films, der nicht nur Obsession, Untreue und Eifersucht abhandelt - Gefühle, die schließlich dazu führen, dass Ferdinand Marianne und dann sich selbst tötet. Die beiden verkörpern auch konkurrierende Glücksentwürfe, die auf Seiten Ferdinands Lektüre und eigenes Schreiben, auf Seiten Mariannes eher eine rezeptiv genießende Hingabe an Musik und Tanz meint. Dabei distanzieren sich beide immer wieder von ihren fiktionalen Rollencharakteren, um selbst zu Erzählern zu werden.

„Sie denkt nur an ihr Vergnügen“, beklagt sich Ferdinand auf der gemeinsamen Fahrt im gestohlenen Cadillac beim Zuschauer. Marianne folgt an dieser Stelle Ferdinands Blick aus dem Bild nicht. Sie scheint das Publikum, an das Ferdinand seine Klage richtet, nicht wahrnehmen, die ästhetische Grenze nicht überschreiten zu können. Erst später, als die Idylle des Strandlebens zerfällt, verlässt sie zeitweise die Intimität des geschlossenen fiktionalen Raums, um ihrerseits per Blick und Monolog Kontakt zum Publikum zu suchen und so aus ihrer Rolle herauszutreten, dann auch selbst zur Erzählerin zu werden. ${ }^{42}$

Der Film ergreift weder Partei für die ernste noch für die Unterhaltungskunst. Keiner der beiden Räume wird als der wahrhaft authentische dem anderen vorgezogen. Vielmehr vermittelt Godard, wie schon angesprochen, eine Wahrnehmung der Kollision zwischen dem unbestimmten, im Paragone von Film und Malerei transportierten ästhetischen Raumentwurf und seiner versuchten Konkretisierung im Handlungsraum der Narration. In dieser Spannung entwickelt sich der spezifische poetisch-subtile Humor von Godards Filmästhetik. Wenn etwa im anfänglichen Vortrag über Velázquez pathetisch von der ,Herrschaft des Raums' die Rede ist, von dem sich ,ohne Ruck' vollziehenden Ineinanderfließen aller Elemente, liefert das simultane Bild von Ferdinand, der ein Bücherkarussell dreht, eine ironische Realisierung jener kosmischen Dynamik, die den Velázquez zugeschriebenen Originalitäts- und Totalitätsanspruch mit lapidarer Wucht aushöhlt. Gleiches gilt für den Spruch von der ,besten aller Welten', der sich bekanntlich auf die gegebene

$42 \mathrm{Vgl}$. Wills (2000), $9 \mathrm{ff}$. und Prange (2010c). Zum Palimpsest-Charakter von Pierrot le fou vgl. Forbes (2000). 
Wirklichkeit bezieht. Ihrer Erfassung widmet sich, mit einer Voltaires Candide vergleichbaren satirischen Schärfe, Godards dokumentarische Bildästhetik.

Die in der malerischen Herrschaft des Raums zitierte und durch die filmischen Bilder des Tennisplatzes, der Nachtlandschaft und schließlich im finalen Blick auf Meer und Sonne eingeholte Ewigkeitsverheißung ruft die modernistische Utopie des von jedem Einzelinteresse abgezogenen erlösenden Fernblicks auf, eines an die Oberfläche der Erscheinung gebannten Sehens. Doch die damit traditionell verbundene Behauptung einer ursprünglichen Wahrnehmung wird ausgehebelt durch die Visualisierung der filmischen Apparatur. Der Stoß, den Ferdinand dem Bücherkarussell gibt, ist ein anderes, mechanisches Bild des Films, das die auditiv präsentierte Metapher des organischen ,Flusses ' der Elemente widerlegt, auch indem es das Zitat, die Adaption und Kombination des im kulturellen Kosmos schon Vorhandenen als einzig mögliche kreative Tätigkeit vorstellt. Godards Kunst der Bezüglichkeit ist eine vollständig andere als die im Velázquez-Kommentar beschworene protoimpressionistische. Nur durch die Trennung von Handlung, Bild und Ton kommt ein ,Fluss` zustande, dem gleichwohl Diskontinuität inhärent ist. Auch die vermeintlich der abstrakten Erscheinung schlechthin gewidmete Schlusseinstellung betont in der langen und langsamen Bewegung der Kamera die mechanische Produziertheit des ,unendlichen' Raums und verflächigt diesen gleichsam durch die Technik der Passierfahrt, die - wenn sie überhaupt im Erzählkino eingesetzt wird, das sie zugunsten zentrierender personenbezogener Kamerabewegungen eher meidet - gewöhnlich einem im Raum aufgerichteten und in seiner Vielgestaltigkeit dokumentierten Sujet gilt. Meer und Himmel erscheinen dagegen, trotz des sich verändernden Bildausschnitts, in ihrer immer gleichen monotonen Größe, am Ende überstrahlt vom Licht der Sonne, so dass die Kameraarbeit als mindestens ebenso selbständiger Bildinhalt erscheint wie das, was sie sichtbar macht.

Der filmische Montageraum kommentiert, reflektiert und ironisiert die auf Ganzheitlichkeit drängenden Atmosphären des singulären Einstellungsraums sowie des scheinbar Kontinuität stiftenden voice overKommentars zu Beginn. Das Ganze des Films wiederum wird konstituiert durch Variation und kritische Durcharbeitung jener ersten Hymne auf die Substanz der Luft, des zwischen den Körpern sich entspannenden räumlichen Gefüges. 


\section{Bibliographie}

Arburg, Hans-Georg von (2010): „,Ein sonderbares Gespinst von Raum und Zeit'. Zur theoretischen Konstitution und Funktion von ,Stimmung' um 1900 bei Alois Riegl und Hugo von Hofmannsthal“. In: Kerstin Thomas (Hg.): Stimmung. Ästhetische Theorie und künstlerische Praxis. Berlin/München: Deutscher Kunstverlag (= Deutsches Forum für Kunstgeschichte/Centre allemand d'histoire de l'art, Passagen/Passages 33), 13-33.

Aumont, Jacques (1990): „The Fall of the Gods: Jean-Luc Godard's Le Mépris (1963)“. In: Susan Hayward/Ginette Vincendeau (Hg.): French Film. Texts and Contexts. London/New York: Routledge, 217-229.

Baby, Yvonne (1972): „Shipwrecked People from the Modern World: Interview with Jean-Luc Godard on Le Mépris“. In: Royal S. Brown (Hg.): Focus on Godard. Englewood Cliffs: Prentice Hall, 37-39.

Badt, Kurt (1956): Die Kunst Cézannes. München: Prestel.

Barr, Charles (1969): The Films of Jean-Luc Godard. London: Studio Vista.

Benjamin, Walter (1936): „Das Kunstwerk im Zeitalter seiner technischen Reproduzierbarkeit (1. Fassung)“. In: ders.: Gesammelte Scbriften. Hg. v. Rolf Tiedemann und Hermann Schweppenhäuser. Bd. 1. Frankfurt a. M.: Suhrkamp, 1991, 431-469.

Benjamin, Walter (1939): „Das Kunstwerk im Zeitalter seiner technischen Reproduzierbarkeit (3. Fassung)“. In: ders.: Gesammelte Schriften. Hg. v. Rolf Tiedemann und Hermann Schweppenhäuser. Bd. 1. Frankfurt a. M.: Suhrkamp, 1991, 471-508.

Bering, Kunibert/Rooch, Alarich (2008): Raum. Gestaltung - Wabrnebmung Wirklichkeitskonstruktion. 2 Bde. Oberhausen: Athena.

Bersani, Leo/Dutoit, Ulysse (2003): Forming Couples. Godard's Contempt. Oxford: Legenda.

Binswanger, Ludwig (1932): „Das Raumproblem in der Psychopathologie“ [1. Fassung]. In: ders.: Ausgewäblte Werke. Vorträge und Aufsätze. Hg. v. Max Herzog. Heidelberg: Asanger, 1994, 123-178.

Böhme, Gernot (1993): „Atmosphere as the Fundamental Concept of a New Aesthetics". In: Thesis Eleven 36, 113-126.

Böhme, Gernot (1999): Theorie des Bildes. München: Fink.

Bollnow, Otto Friedrich (1941): Das Wesen der Stimmungen. Frankfurt: V. Klostermann, ${ }^{8} 1995$.

Bollnow, Otto Friedrich (1963): Mensch und Raum. Stuttgart: Kohlhammer, ${ }^{10} 2004$.

Brody, Richard (2008): Everything Is Cinema. The Working Life of Jean-Luc Godard. London: Faber \& Faber.

Brown, Royal S. (1972): „Nihilism versus Aesthetic Distantiation“. In: ders. (Hg.): Focus on Godard. Englewood Cliffs: Prentice Hall, 109-122.

Busch, Werner (1995): „Studien vor der Natur“. In: Christoph Vitali (Hg.): Ernste Spiele. Der Geist der Romantik in der deutschen Kunst 1790-1990. Ausst.-Kat. Haus der Kunst, München vom 4. Februar bis 1. Mai 1995. Stuttgart: Oktagon, 463-466.

Cerisuelo, Marc (2006): Le Mépris. Chatou: Les éditions de la Transparence.

Coates, Paul (1988): „Le Mépris: Women, Statues, Gods“. In: Film Criticism 3, 38-50.

Dixon, Wheeler W. (1997): The Films of Jean-Luc Godard. Albany: State Univ. of New York Press, 
Elger, Dietmar, Hg. (1999): Gerhard Richter. Landschaften. Ausst.-Kat. Sprengel Museum Hannover, 4. Oktober 1998 - 3. Januar 1999. Ostfildern-Ruit: Ed. Cantz.

Eliade, Mircea (1984): Das Heilige und das Profane. Vom Wesen des Religiösen. Frankfurt a. M.: Insel.

Engell, Lorenz (2003): Bilder des Wandels. Weimar: vdg (= serie moderner film 1).

Forbes, Jill (2000): „Pierrot le fou and Post-New Wave French Cinema“. In: David Wills (Hg.): Jean-Luc Godard's „Pierrot le fou“. Cambridge: UP, 108-132.

Godard, Jean-Luc (1966): Eine verheiratete Frau. Protokoll. Hamburg: Verl. Filmkritik (= Cinemathek 15$)$.

Godard, Jean-Luc (1972): Godard on Godard. Critical Writings by Jean-Luc Godard. Hg. v. Jean Narboni u. Tom Milne. New York/London: Secker \& Warburg.

Godard, Jean-Luc (1979): Reibe Film 19. München/Wien: Hanser.

Godard, Jean-Luc (1992): Einführung in eine wabre Geschichte des Kinos. Frankfurt a. M.: S. Fischer.

Kilb, Andreas (1990): „Abschied vom Mythos. Über Le Mépris von Jean-Luc Godard (1963) und über den Wandel der Filmkritik“. In: Norbert Grob/Karl Prümm (Hg.): Die Macht der Filmkritik. Positionen und Kontroversen. München: Edition Text + Kritik, 184-197.

Kinder, Marsha (1981): „A Thrice-Told Tale. Godard's Le Mépris (1963), from the Novel $A$ Gbost at Noon by Alberto Moravia“. In: Andrew Horton/Joan Magretta (Hg.): Modern European Filmmakers and the Art of Adaptation. New York: Frederick Ungar Publishing, 100-114.

Lefebvre, Henri (1991): The Production of Space. Übers. v. Donald NicholsonSmith. Oxford u. a.: Blackwell. Franz. Orig.: La production de l'éspace. Paris: Anthropos, 1974.

Lindner, Burkhardt, Hg. (2006): Benjamin Handbuch. Leben - Werk - Wirkung. Stuttgart/Weimar: Metzler.

Magritte, René (1985): „Die Lebenslinie (I)“. In: ders.: Sämtliche Schriften. Hg. v. André Blavier. Frankfurt a. M./Berlin: Ullstein, 42-96.

Marie, Michel (2006): Comprendre Godard. Travelling avant sur "A bout de souffle " et „Le Mépris“. Paris: A. Collin.

Pantenburg, Volker (2006): Film als Theorie. Bildforschung bei Harun Farocki und JeanLuc Godard. Bielefeld: transcript.

Prange, Regine (1993): „Hinüberbauen in eine jenseitige Gegend. Paul Klees Lithographie Der Tod für die Idee und die Genese der Abstraktion“. In: WallrafRichartz-Jabrbuch 54, 281-314.

Prange, Regine (2006): Das ikonoklastische Bild. Piet Mondrian und die Selbstkritik der Kunst. München: Fink.

Prange, Regine (2010a): „Sinnoffenheit und Sinnverneinung als metapicturale Prinzipien. Zur Historizität bildlicher Selbstreferenz am Beispiel der Rückenfigur". In: Verena Krieger/Rachel Mader (Hg.): Ambiguität in der Kunst. Typen und Funktionen eines ästhetischen Paradigmas. Köln u. a.: Böhlau (= kunst geschichte - gegenwart 1), 125-168.

Prange, Regine (2010b): „Konjunkturen des Optischen - Riegls Grundbegriffe und die Kanonisierung der künstlerischen Moderne“. In: Peter Noever u. a. (Hg.): Alois Riegl Revisited. Beiträge zu Werk und Rezeption. Wien: Verlag der Österreichischen Akademie der Wissenschaft (= Veröffentlichungen der Kommission für Kunstgeschichte 9), 109-128.

Prange, Regine (2010c): „Der Blick aus dem Bild im Medienvergleich. Zur Reflexion der ästhetischen Grenze bei Paul Klee und Jean-Luc Godard“. In: Marc Greenlee u. a. (Hg.): Aisthesis. Wabrnebmungsprozesse und Visualisierungsformen in 
Kunst und Technik. Regensburg: Schnell \& Steiner (= Regensburger Studien zur Kunstgeschichte 12; im Ersch.).

Prange, Regine (2010d): „Genre und Genrekritik. Der Western in Jean-Luc Godards $A$ bout de souffle (1959)“. In: Ursula Frohne/Ursula Haber (Hg.): Kinematographische Räume. München: Fink (im Ersch.).

Richter, Gerhard (1993): Katalog anl. der Ausstellung Gerhard Richter im Musée d'Art Moderne de la Ville de Paris, 23. September bis 21. November 1993. $\mathrm{Hg}$. v. der Kunst- und Ausstellungshalle der Bundesrepublik Deutschland. 3 Bde. Ostfildern-Ruit: Ed. Cantz.

Riegl, Alois (1899): „Die Stimmung als Inhalt der modernen Kunst“. In: ders.: Gesammelte Aufsätze. Augsburg/Wien: Luther, 1929, 28-39.

Schelling, Friedrich Wilhelm Joseph (1807): „Über das Verhältniß der bildenden Künste zu der Natur“. In: ders.: Ausgewäblte Schriften. Bd. 2. Frankfurt a. M.: Suhrkamp, 1985, 579-619.

Schleicher, Harald (1991): Film-Reflexionen. Autothematische Filme von Wim Wenders, Jean-Luc Godard und Federico Fellini. Tübingen: Niemeyer (= Medien in Forschung + Unterricht. Serie A 32).

Sylvester, David, Hg. (1992): René Magritte. Catalogue raisonné. London: Wilson.

Souriau, Etienne (1951): „La structure de l'univers filmique et le vocabulaire de la filmologie“. In: Revue internationale de Filmologie 2, 231-240.

Vacche, Angela dalle (1995): „Jean-Luc Godard's Pierrot le fou. Cinema as Collage against Painting“. In: Literature-Film Quarterly 23, 39-54.

Vimenet, Pascal (1991): Le Mépris . Jean-Luc Godard. Un film produit par Georges de Beauregard. Paris: Hatier.

Wills, David (2000): „Introduction“. In: ders. (Hg.): Jean-Luc Godard's „Pierrot le fou". Cambridge: UP, 1-22.

Wulf, Christoph (1987): „Die Liebesflamme“. In: Dietmar Kamper/ders. (Hg.): Das Heilige. Seine Spur in der Moderne. Frankfurt a. M.: Athenäum (= Die Weiße Reihe), 328-337. 